\title{
Controversies surrounding diet and breast cancer
}

\author{
BY LENORE KOHLMEIER AND MICHELLE MENDEZ
}

Departments of Epidemiology and Nutrition, School of Public Health, University of North Carolina at Chapel Hill, Chapel Hill, North Carolina 27599-7400, USA

Breast cancer, which continues to rob the world of approximately half a million women per year, is surprisingly poorly understood. Despite application of all the tools of epidemiology: ecological studies, migrant studies, case-control and cohort studies, and measurement of multiple exposures at various times of life, we still cannot advise women on how to protect themselves or their daughters from breast cancer. The disease has a familial and a hormonal component, but current knowledge of these components does not adequately explain breast-cancer risk. In the search for strategies to prevent this devastating disease, potential food-borne exposures have been studied in both animal models and in women. These include studies of the relationship of the macronutrients (fat, and alcohol, as well as total energy intake), studies of antioxidant micronutrients, studies of body fat and oestrogen levels, and studies of specific foods (such as cruciferous vegetables and soyabean products). Even substances carried by food, such as the pesticide dichloro-diphenyltrichlorethane (DDT), have received and continue to receive scrutiny. The present paper will attempt to summarize current knowledge and belief in the area of these food-borne exposures.

\section{DIETARY FAT, ENERGY INTAKES AND BREAST CANCER}

The involvement of dietary fat as a risk factor for breast cancer remains controversial. There seems to be a strong and consistent relationship between per capita average total fat disappearance and breast-cancer incidence, when assessed in international ecological studies (Prentice \& Sheppard, 1989). However, results of case-control and cohort studies in which diet was assessed by food-frequency questionnaire are inconsistent. The controversy surrounding this has focused in part on colinearity with energy intakes (Palmgren, 1993). Particularly after adjustment for energy intakes, the independent effect of total dietary fat intakes appears to be minimal if existent at all (Hulka, 1989).

The importance of fat intake to breast cancer needs to be examined both in its role as a contributor of energy, and in its potential for influencing risk independent of an energy effect. Non-energy-adjusted models ask whether absolute intakes of fat contribute to breast cancer, either through an association with energy intakes or otherwise. Energy-adjusted models ask something much more subtle: to what extent does the amount of fat consumed, beyond that expected of a woman at her reported energy intake level, relate to breastcancer risk, when fat is exchanged isoenergetically for other nutrients? Some animals, such as rats, do appear to adjust their energy intake to the nutrient density of their feed (Braden \& Carroll, 1986). Hamsters, on the other hand, will substantially increase body weight if fed on a fat-rich diet ad libitum (Birt et al. 1989). Human subjects are unfortunately more like hamsters: in free-living human populations, as with caged hamsters, dietary fat is rarely exchanged isoenergetically for other macronutrients. Instead, people consuming more fat tend to consume more total energy and become fatter (Astrup et al. 1995). Therefore, the public health importance of the contribution of fat to total energy intakes remains strong, even if the effect is through total energy intake. 
Energy-adjusted models are justified when biological hypotheses suggest that fat, above and beyond its contribution to energy intake, contributes to breast-cancer risk. This might be the case if fat carries carcinogens (for example, pesticides) or if certain types of fat are particularly biologically active. Examples of the difference in hypotheses are expressed in Fig. 1.

In animal models, total energy intake remains one of the most important predictors of carcinogenesis (Albanes, 1987). In epidemiological studies, which are subject to biased reporting of intakes, the association is less consistent (Howe et al. 1990; Hunter et al. 1996). This may be due to a differential under-reporting of food consumption among more obese women (Lichtman et al. 1992), or greater energy intakes among the most-physicallyactive women.

Pooled analyses of case-control studies from eight countries with approximately 4400 cases of breast cancer show a $25 \%$ increase in breast-cancer risk associated with a $100 \mathrm{~g} / \mathrm{d}$ increase in fat intake. Since $100 \mathrm{~g}$ fat represents $3.8 \mathrm{MJ}$ or approximately $40 \%$ of the total energy requirement of a normal woman, changes of this magnitude are unlikely (Howe et al. 1990). A pooled analysis of cohort studies of breast cancer from four countries and including approximately 4980 cases found a relative risk of a similar magnitude, with an increase in risk of $7 \%$ per $25 \mathrm{~g}$ fat after deattenuation (Hunter et al. 1996). This increase in risk, however, was not statistically significant. For the most part, these cohort studies examine post-menopausal diets in relation to post-menopausal breast-cancer risk. None of these studies addresses the question as to whether fat-rich diets in childhood and during puberty are related to breast-cancer risk in adulthood.

\section{INDIVIDUAL FATTY ACIDS AND BREAST CANCER}

Epidemiological studies that calculate risk ratios for total fat fail to take into account the biological non-equivalence of the various types of fatty acids. Studies of the metabolic relationships of fat intake and human blood lipids have shown how important it is to allow for the differences in individual fatty acids, since different families and specific fatty acids within families have biological effects which differ both in their magnitude and the direction of effect on eicosanoid production as well as on carcinogenesis in animal models. The confusion and conflicting results regarding fat intake may be due to the physiological importance of individual fatty acids which are generally inadequately separated in human studies.

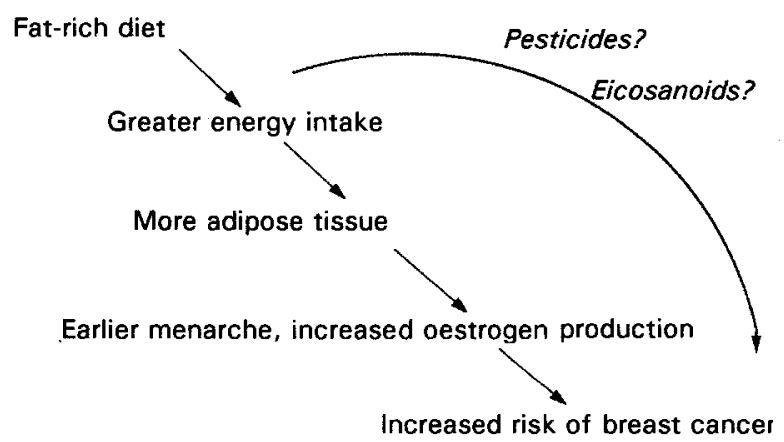

Fig. 1. Alternative mechanisms underlying a fat-breast cancer relationship. 
Few studies have examined the components of fat, individual fatty acids, or classes such as short-, medium- and long-chain fatty acids, trans-fatty acids, or various of monoand polyunsaturated fatty acids in relation to breast cancer. This is largely due to the difficulty in estimating intakes, which are a function of sources of oils and fats, types of fish, and other facets of the diet which are poorly known to the consumer. Dietary assessment tends to remain at the level of consumption of types of foods, such as olive oil or fish; and not their fatty acid compositions. These foods can carry other substances, such as phenols, which may account for any association with risk or any protective effects.

It is generally difficult to obtain accurate information on dietary intakes in epidemiological studies (Barrett-Connor, 1991). Intake of foods, when assessed by interview or questionnaire, may be recalled differentially between cases and controls. The use of food-composition tables may also introduce errors, because of large variations in nutrient content of some foods. Furthermore, when measuring intake, individual variation in absorption and metabolism is not taken into account. Intakes of fatty acids pose even greater problems than many other nutrients.

Where available, molecular markers of intake often are preferable. Plasma or serum concentrations are used most often (Bates \& Thurnham, 1991). Although adipose-tissue analysis is a reliable alternative to dietary records and probably superior for the assessment of diet in the distant past, few biomarker studies of the profiles of individual fatty acid stores in adipose tissue or other media exist to date (Kohlmeier \& Kohlmeier, 1995; Kohlmeier, 1997). The relative abundance of individual fatty acids in adipose tissue reflects the composition of habitual diet. One of the few large studies of breast cancer to use biomarkers of adipose tissue as a long-term integrated biomarker of dietary intakes is the European Community Multicentre Study on Antioxidants, Myocardial Infarction and Cancer of the Breast (EURAMIC) Study.

\section{EURAMIC STUDY}

Between 1990 and 1992 a multi-national case-control study was conducted in five European countries: Northern Ireland, Germany, The Netherlands, Spain and Switzerland. The incidence of breast cancer has an approximately twofold range between countries (3872 per 100000) with the lowest risk of disease in Spain. The purpose of this study was to examine potential protective roles of antioxidants in the development of breast cancer. A common protocol for recruitment, sampling and exposure assessment was developed. The participating physicians in this study were trained in the sampling techniques with written and videotaped instructions. Technicians were trained in sample handling, and all samples were transported to the coordinating centre. Central laboratory analyses were the core of this study: the levels of carotenoids, tocopherols and fatty acid composition of the glutealadipose-tissue samples were determined in the laboratories of the Toxicology and Nutrition Institute in Zeist, The Netherlands.

The specific purpose of the EURAMIC study was to relate the levels of fat-soluble antioxidant nutrients and $\mathrm{Se}$ in tissues with a low turnover, which provide biomarkers of the integrated long-term intake of these nutrients, to risk of breast cancer. The central hypothesis was that concentration of $\alpha$-tocopherol and $\beta$-carotene in adipose tissue, and of $\mathrm{Se}$ in toenails is lower in newly-diagnosed breast cancer cases as compared with healthy population controls (Kardinaal et al. 1993). In addition, the study developed a component to examine relationships between stores of individual fatty acids and risk of breast cancer. 700 cases and controls from five diverse European countries were enrolled in this multicentred case-control study. The biomarker-based findings from this study on the relationship between dietary factors and breast-cancer risk are presented below. 


\section{MONOUNSATURATED FATS AND BREAST CANCER}

Most of the studies on monounsaturated fats actually focus on the differences in consumption of olive oil between groups of women. A number of epidemiological studies of olive oil and breast-cancer risk have pointed to a protective effect among women who consume olive oil more frequently. Women consuming olive oil more than once daily have breast-cancer risks which are up to one-third lower than that of the non-consumers in Italy, Greece and Spain (Martin-Moreno et al. 1994; LaVecchia et al. 1995; Trichopolou et al. 1995). Olive oil is, however, a complex product containing various levels of monounsaturates, and vastly differing amounts of vitamin $E$, depending on the source tree and where it is located. The consumption of olive oil may also be strongly associated with socio-economic status, or other dietary characteristics, such as lower usage of butter or margarine. In epidemiological studies of diet which calculate all sources of monounsaturates, and in biomarker studies, intake of monounsaturates per se is not associated with lower breast-cancer risks (Kohlmeier, 1997).

\section{POLYUNSATURATED FATTY ACIDS}

Animal models of cancer using chemical carcinogens can generally not produce tumours in the absence of $n-6$ fatty acids. This source of essential fatty acids is known to regulate synthesis of prostaglandins, which in turn can regulate tumour growth, metastases, and can suppress host immune responsiveness (Nogushi et al. 1995).

$n-3$ Fatty acids (largely fish oils) are seen, when consumed in high amounts, to be inhibitory of tumourigenesis. As with olive oil, consumption of the source food (fish), is often taken as a surrogate for $n-3$ consumption. The problem with this is that, depending on the type of fish consumed, and its preparation style, consumption can be poorly, and, in some cases, negatively associated with erythrocyte membrane levels of long-chain $n-3$ fatty acid concentrations (Olsen et al. 1995). This may be a function of low intake levels, or the contribution of other fats being consumed, for example, with breaded, fried fish products.

It is becoming increasingly clear that the production of active eicosanoids is regulated by the type of precursor fatty acid. Prostaglandins of the 2-series and leukotrienes of the 4series are produced from $n-6$ fatty acids, whereas the respective 3 - and 5-series are derivatives of $n-3$ fatty acids (Fig. 2). The latter are known to reduce chemically-induced breast-cancer growth in rats (Nogushi et al. 1995). This may be through inhibition of oxidative metabolism of arachidonic acid via the cyclooxygenase pathway of prostaglandin synthesis. However, the actual function of individual fatty acid metabolites in women is not clear, and the mechanisms by which fatty acids stimulate or inhibit tumours remain controversial.

The rate-limiting enzyme, $\delta$-6-desaturase, shows a greater affinity for fatty acids of the $n-3$ family. The result of this is production of eicosanoids which are very similar in structure, but can be antagonistic to those produced from the $n-6$ fatty acid family. Examples of this are the aggregating and vasocontricting effects of thromboxane $A 2$ from the $n-6$ family, and the anti-aggregating effects of thromboxane A3 from the $n-3$ family.

Evidence is accumulating which suggests that more important than the absolute amount of a fatty acid is its concentration relative to that of its competitors in lipooxygenase ( $E C$ 1.13.11.12) and cyclooxygenase pathways of eicosanoid production. Preliminary results from the EURAMIC study suggest that a higher relative concentration of $n-3$ fatty acids may be protective (Simonsen et al. 1996). 


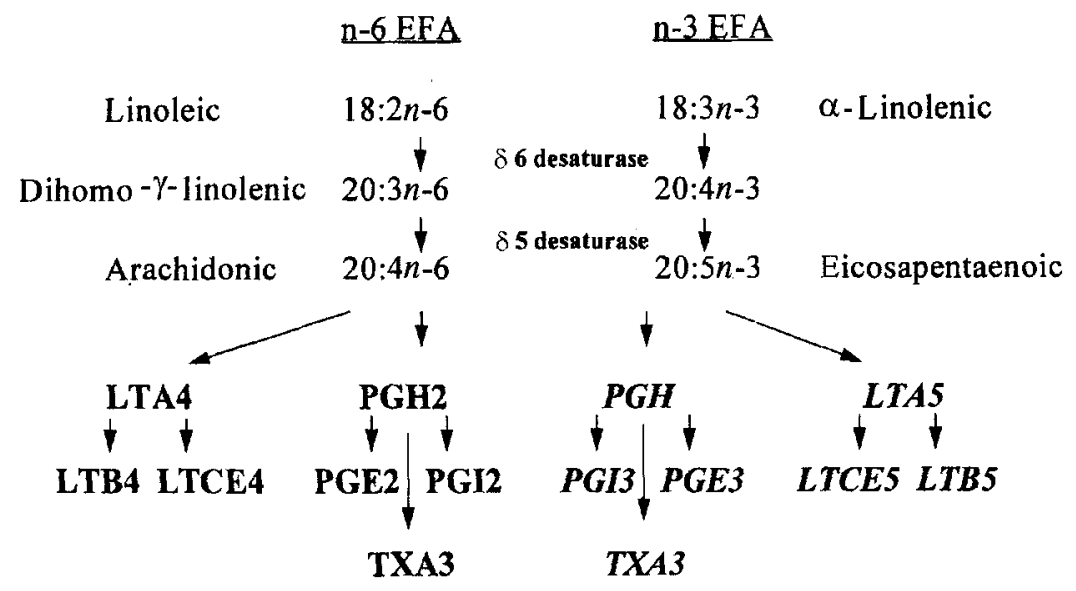

Fig. 2. Pathways of $n-6$ and $n-3$ essential fatty acid (EFA) metabolism. LT, leukotrienes; PG, prostaglandin; TX, thromboxanes.

\section{TRANS-FATTY ACIDS AND BREAST CANCER}

Trans-fatty acids are formed largely through the hydrogenation of vegetable oils to enhance stability. They are produced enzymically to some degree naturally, but the majority of trans-fats in Western populations are consumed in processed foods. These fatty acids are known to have the ability to impair microsomal desaturation and elongation of essential fatty acids to their long-chain polyunsaturated metabolites. They compete for desaturase enzyme sites and potentially reduce production of the 3-series eicosanoids (Kinsella et al. 1979; de Schrijver \& Privett, 1982; Lawson et al. 1983; Mahfouz et al. 1984; Koletzko, 1992). Although there has been considerable study of the effects of intakes of trans-fatty acids on lipoprotein metabolism and cardiovascular disease, only two studies have examined relationships between trans-fatty acid stores and cancer in human subjects. In a study of Americans in whom stores of trans-fatty acids are twice as high as those in Europe, increases in risk were found at some levels of greater trans-fatty acid intake, although without an overall linear trend (London et al. 1993). Within the EURAMIC study an increase in risk of breast cancer has been found among those women with greater stores of trans-fatty acids (Kohlmeier et al. 1995).

\section{ANTIOXIDANTS AND BREAST CANCER}

Serious adverse effects arise in the presence of excessive concentrations of oxygen beyond the normal need for oxidative processes to support life, or in the absence of adequate antioxidant protection. These effects include peroxidation of membrane lipids, the hydroxylation of nucleic acid bases and the oxidation of protein moieties.

Oxidative stress is enhanced by inflammation, exercise, radiation exposure, surgery, air pollution, reperfusion, cigarette smoking and dietary intakes of polyunsaturated fatty acids. The endogenous sources of oxidants include normal respiration, phagocytosis, cytochrome P450 enzymes, and peroxisomes. The degradation of fatty acids by peroxisomes can cause the release of peroxide into other cell compartments and result in oxidative DNA damage. Fatty acid oxidation can also directly cause oxidative damage through lipid peroxidation, 
the creation of mutagenic lipid epoxides, lipid hydroperoxides, lipid alkoxyl and peroxyl radicals and enals (Ames et al. 1993). As quenchers of free radicals, naturally-occurring antioxidants such as carotenoids and tocopherols can theoretically block potential DNA damage caused by free radicals.

A multitude of epidemiological studies have provided evidence that eating behaviour patterns consistent with a high fruit and vegetable intake carry lower cancer risks (Block $e t$ al. 1992). However, the association between intake of fruits and vegetables rich in carotenoids, or plasma carotene levels, and a decreased risk of cancer appears to be most consistent for lung cancer and stomach cancer (Gey et al. 1987; Wald et al. 1988; Connett et al. 1989) and less consistent for cancers of the breast (Wald et al. 1984; Paganini-Hill et al. 1987; Rohan et al. 1988; Potischman et al. 1990; Comstock et al. 1991). Since carotenoids serve as markers of other dietary factors in the same source foods, which may actually be responsible for the protective effects seen for certain dietary patterns, and there is little evidence of a specific $\beta$-carotene association, it appears unlikely that any of the polyphenols in fruits and vegetables currently under investigation will turn out to be strong predictors of breast-cancer risk.

Attention in epidemiological studies has focused on studying whether $\beta$-carotene intakes are protective. At least seven studies have reported on the plasma concentrations of $\beta$-carotene as a function of breast-cancer risk (Willett et al. 1984; Knekt, 1988; Marubini et al. 1988; Wald et al. 1988; Basu et al. 1989; Potischman et al. 1990; London et al. 1991). Lower mean concentrations were found in cases in three of these studies (Gey et al. 1987; Basu et al. 1989; Potischman et al. 1990); however, the difference was only significant in one of these studies (Potischman et al. 1990). Many of these studies were rather small and so lacked the power to detect a difference. In most studies, the diets of the women enrolled were quite homogeneous, which might mask a true effect. To assess the public health significance of antioxidants, and to provide recommendations on their use as preventives, requires epidemiological research on the modulators and effects of these substances. It is also vital that studies have adequate power, and are conducted in populations with sufficient variance in exposure using objectively-determined exposure levels. The EURAMIC study, which addresses a number of the limitations of geographically-insular epidemiological studies, also found little evidence of an important role for $\beta$-carotene in breast-cancer risk (van't Veer et al. 1996).

Analyses from the EURAMIC study revealed two surprises: first, the concentrations of $\beta$-carotene in the adipose tissue were lowest among women in the southern-most countries, where rates of breast cancer were the lowest. It would have been expected that levels in these women would be the highest from their diets, which are richer in fruits and vegetables than in the northern countries. Second, no protective effect of high adipose stores of either $\beta$-carotene or $\alpha$-tocopherol, or from a combination of antioxidants, was seen. In fact, the direction of the $\alpha$-tocopherol effect, although not statistically significant, was contrary to expectations.

\section{CRUCIFEROUS VEGETABLES AND BREAST CANCER}

The modulation of carcinogenesis by the consumption of cruciferous vegetables has been investigated in laboratory animals that were exposed to known carcinogens. Tumour development has often been compared in animals with and without cabbage-supplemented diets (Wattenberg, 1983; Birt et al. 1987; Temple \& Basu, 1987; Temple \& el Khatib, 1987; Scholar et al. 1989). A number of these studies provide evidence of an effect on the production of some tumours. Incidence of mammary tumours, particularly in mice and rats, 
seemed to be reduced on the addition of $5-20 \%$ of cabbage by weight to the diet (Stoewsand et al. 1988; Bresnick et al. 1990).

The active ingredients in Crucifera have not been definitively determined. Among the more than 2000 naturally-occurring compounds in Brassica (Huang \& Ferraro, 1992), phenolic compounds have drawn attention. The action of some flavonoids is mediated by binding to oestrogen receptors which may regulate gene transcription and protect against certain cancers (Baker, 1992). Among the phenols, dithiolthiones and the isothiocyanates formed on cleavage of glucosinolates are among the strongest inducers of quinone reductase (EC 1.6.99.2), an important detoxifying phase-II-enzyme (Prestera et al. 1993). Isothiocyanates stimulate acutely the activity of a wide range of phase-II-enzymes. The induction of glutathione-S-transferase (EC 2.5.1.18) and glucuronidase may enhance the excretion of carcinogens through the bile and urine. The net effect of this induction may be chemoprotective, but that remains to be proven. 1,2-Dithiol-3-thiones, which occur naturally in Brassica, are under study in clinical trials as chemoprotective agents (Ansher $e t$ al. 1986). It should be noted that both pro- and anti-carcinogenic activities have been ascribed to indole derivatives and isothiocyanates (McDanell et al. 1989).

More closely related to breast-cancer risk in particular is the study of the effect of indole-3-carbinol on oestrogen metabolism. Indole-3-carbinol has been shown to be antiproliferative in cell systems (Newfield et al. 1993). The balance of C-16 $\alpha$-hydroxyoestrone to $\mathrm{C} 2$ hydroxyoestrone, i.e. the ratio, fully-potent : weakly-anti-oestrogenic oestrogens, is being studied as a potential mechanism. Feeding of pure indole-3-carbinol reduces the ratio 16 2 2-hydroxylation: 2-hydroxylation of oestradiol (Michnovicz \& Bradlow, 1991; Telang et al. 1992). This is the inverse of the effect expected from oestrogenic pesticides, as described later (p. 376).

\section{XENO-OESTROGENS}

Recently, it has been suggested that exposure to environmental oestrogens may be related to risk of breast cancer. These xeno-oestrogens have been linked to the hypothesis that cumulative exposure to oestrogens plays a role in breast-cancer aetiology. Two of the xenooestrogens under study involve exposure through the diet: phyto-oestrogens, which are naturally-occurring plant compounds, and organochlorine pesticides such as DDT, which persist in the environment and may be ingested in foods as well as through the skin and respiratory tract. Both groups of compounds have been shown to affect oestrogen metabolism in vivo and in vitro. While phyto-oestrogens are believed to reduce the risk of breast cancer because of their low potency relative to endogenous oestradiol, organochlorine pesticides have been hypothesized to amplify oestrogen activity, increasing risk.

\section{Phyto-oestrogens}

Interest in phyto-oestrogens as potential anti-carcinogens has evolved largely in response to the suggestion that high intakes of soyabean foods may contribute to the lower incidence of breast cancer in Japan, China, and other countries in Asia. These foods are not a traditional part of Western diets. Soyabeans are a rich source of isoflavones, one of two classes of phyto-oestrogens which are important in the human diet. Soyabeans have by far the highest concentration of isoflavones, which are found mainly in legumes; chick peas (Cicer arietinum) are another dietary source. Genistein, the most extensively studied isoflavone, is the main isoflavone in soyabeans, accounting for two-thirds of soyabean 
isoflavone content (Messina et al. 1994). Lignans, another important type of phytooestrogen, are derived from the metabolism of lignins (found in plant cell walls), and are produced from almost all cereals and vegetables.

Phyto-oestrogens bind to oestrogen receptors, but induce less potent oestrogen activity than endogenous oestrogens. Plant oestrogens are believed to reduce risk of breast cancer through their net anti-oestrogenic effect. Effects of these compounds on hormone metabolism have been shown in both human subjects and animals. Soyabean consumption increases menstrual cycle length and decreases circulating levels of oestradiol in human subjects (Lu et al. 1996). A 1994 review of epidemiological studies on phyto-oestrogens and breast cancer reported that three of four studies on intakes of various soyabean foods and breast cancer found statistically significant inverse relationships (Messina et al. 1994). One of these found protective associations only in pre-menopausal women. The study which found no relationship used fat from soyabean products as the measure of exposure (Hirohata et al. 1985). Data from animal and in vitro experiments with mammary cancers also suggest that soyabean may be protective (Messina et al. 1994). However, results of recent studies on genistein reveal an oestrogen agonistic effect resulting in proliferation of oestrogen-dependent human breast-cancer cells and enhanced tumour growth at low concentrations (Helferich, 1996). Thus, here too, the story remains unclear regarding a net protective effect of consumption of soyabean in breast-cancer incidence or recurrence.

At this time, associations between breast-cancer risk and consumption of soyabean foods are not definitively linked to oestrogen bioavailability. Since soyabean foods contain other substances which may be anti-carcinogens, it is possible that non-oestrogenic properties of flavonoid-containing foods (e.g. antioxidant or anti-mutagenic properties) may contribute to a reduction in cancer risk. Evidence of a protective effect of soyabean products on non-hormonal cancers lends support to this alternative hypothesis, and argues against an oestrogen-related effect. Associations with soyabean product consumption may also be confounded by other dietary patterns or specific food items for which consumption is strongly correlated with soyabean intakes. Further study is needed to confirm the existence of a protective effect of soyabean and other foods rich in phyto-oestrogens, and to determine what properties of soyabean foods may be responsible for any effects.

\section{Organochlorine pesticides}

Research conducted to date has focused on the pesticide DDT and its metabolite, 1,1dichloro-2,2-bis(p-chlorophenyl) ethylene (DDE). DDT use has been banned for some time in most industralized countries, but it continues to be widely-used in many developing nations. Although levels are declining in countries where use has been banned, DDT remains ubiquitous in the environment due to its long half-life. Because its use has been discontinued, current levels of DDT in the food chain in industrialized countries are believed to be low. The low level of exposure, and the relatively low potency of organochlorine chemicals compared with other oestrogens, has led some researchers to argue that these chemicals are unlikely to be important health hazards (Safe, 1995).

DDT and DDE are fat-soluble and, therefore, accumulate and persist in the environment and in human adipose tissue. These compounds are believed to mimic oestrogen activity in the body. Unlike phyto-oestrogens, organochlorines are expected to increase net exposure to biologically-active oestrogen. In the laboratory, organochlorines increase the hydroxylation of oestradiol to 16- $\alpha$-hydroxyoestrone, a potently active form of oestrogen, altering the ratio, 16- $\alpha$-hydroxyoestrone: 2 -hydroxyoestrone, a less-active metabolite (Davis \& Bradlow, 1995). Elevated levels of the more active form of oestrogen 
have been found in breast tumours, suggesting a possible causal link (Davis \& Bradlow, 1995).

Epidemiological studies on DDE and risk of breast cancer have provided equivocal results. Positive relationships have been reported in three case-control studies (Falck et al. 1992; Wolff et al. 1993; Dewailly et al. 1994), but these results have been based on small sample sizes (from thirty-five to 229 subjects). Odds ratios reported in these studies ranged from 2 to greater than 10 . These positive relationships have not been confirmed by three larger, more recent studies (300-606 subjects), including two studies which measured DDE levels an average of 14 years or more before diagnosis (Krieger et al. 1994; Sutherland et al. 1996). In one of these studies (Krieger et al. 1994), however, there were positive relationships within individual ethnic group strata. Serum DDE levels were elevated in Caucasian and in African-American women with breast cancer relative to controls of the same ethnicity, while higher DDE levels appeared protective in Asians (Krieger et al. 1994). Preliminary results from the EURAMIC study, which measured levels in gluteal adipose tissue, also fail to support a causal link (Lobbezoo et al. 1997).

To date, no strong and consistent effect of pesticide exposure has been identified. Two of the three studies which found positive associations between breast cancer and pesticide exposure (Wolff et al. 1993; Dewailly et al. 1994) relied on measures of DDE in serum or plasma obtained shortly before (6 months) or after diagnosis. In these studies, the possible influence of cancer-related changes in metabolism or weight cannot be excluded as reasons for the elevated levels in cases. Furthermore, exposures earlier in life may be more relevant for risk of breast cancer (Wolff \& Toniolo, 1995). The studies which measured blood levels prospectively did not confirm positive associations. The two studies using adipose tissue levels of DDE also found inconsistent results (Falck et al. 1992; Lobbezoo et al. 1997). However, because of the small size of the pilot study, Falck et al. (1992) and others, who found elevated DDE in cases relative to controls, were not able to adjust for potential confounding factors.

\section{ALCOHOL}

The epidemiological literature on alcohol consumption and risk of breast cancer generally supports a weak causal association (Longnecker, 1994; Hunter \& Willett, 1996). Relative risks reported in the literature are variable, but on the whole suggest that mean intakes of as little as one drink daily may be harmful. In a recent meta-analysis, the odds ratio for one drink daily was estimated to be $1.11(95 \% \mathrm{CI} 1.07-1.16)$, and $1.24(95 \% \mathrm{CI} 1.15-1.34)$ for two drinks daily, with stronger relationships for increasing levels of consumption (Longnecker, 1994). Even a small increase in risk is potentially of public health significance, since moderate drinking is a common, modifiable exposure.

A number of pathways through which ethanol, the active constituent of alcoholic beverages, may increase risk of breast cancer have been suggested, although at this time the mechanisms are not well understood. Ethanol itself is not a carcinogen, but is converted to a potentially carcinogenic metabolite (acetaldehyde) in the body. Alcohol has also been associated with oxidative stress in the liver, which may induce the activity of other enzymes, resulting in increased production of carcinogenic metabolites. Ethanol has also been shown to increase the permeability of cells to other potential carcinogens (Thomas, 1995). Animal studies suggest that ethanol consumption can stimulate cell proliferation in mammary tissue, which may increase risk of benign breast disease and cancer. Recently, ethanol has been shown to increase circulating plasma oestrone and oestradiol levels in premenopausal women (Reichman et al. 1993). This suggests that drinking alcohol elevates 
exposure to bioavailable oestrogens, providing another possible link with the hormonal pathways hypothesized to be involved in the aetiology of breast cancer.

Poor understanding of the mechanisms complicates measurement of the relevant dimension of alcohol drinking for breast-cancer research: the timing, amounts and types of alcoholic beverages which are relevant for risk of breast cancer are not known. Most studies have measured average consumption of ethanol in the recent past, perhaps 5-10 years before diagnosis. However, adolescent drinking, or drinking during early adulthood, may be more important determinants of risk. A few studies (Harvey et al. 1987; van't Veer et al. 1989; Young, 1989; Longnecker et al. 1995a,b) have explored the effects of early drinking habits; most of these studies suggest that there may be risk associated with drinking before age 30-35 years independent of later drinking. Past drinking was associated with increased risk of breast cancer in the EURAMIC study (odds ratio 1.73, (95\% CI 1.07-2.79); M. A. Royo-Bordonana, J. M. Martin-Moreno, E. Guallar, L. Gorgoja, P. van't Veer, M. Mendez, J. K. Huttunen, B. C. Martin, A. F. M. Kardinaal, J. Fernandix-Crehuet, M. Thamm, J. J. Strain, F. J. Kok and L. Kohlmeier, unpublished results). Patterns of drinking, bingeing $v$. regular consumption, may also be important, but have not been explored. Types of beverages with different constituents, wine, beer and spirits, may also have different effects on breast-cancer risk, although the literature to date does not seem to indicate important heterogeneity by type (Longnecker, 1994).

A few studies have suggested the effect of a threshold at two to three drinks $(30 \mathrm{~g})$ daily (Garfinkel et al. 1988; Toniolo et al. 1989; Howe et al. 1991), but this hypothesis has not been consistently supported in the literature. Results from the EURAMIC study, which excluded heavy drinkers, may be consistent with a threshold effect. Mean alcohol intakes among current drinkers ranged from 3.0 to $14.0 \mathrm{~g} / \mathrm{d}$ in the EURAMIC population, and there was no significant increase in risk of breast cancer associated with current drinking (M. A. Royo-Bordonana, J. M. Martin-Moreno, E. Guallar, L. Gorgoja, P. van't Veer, M. Mendez, J. K. Huttunen, B. C. Martin, A. F. M. Kardinaal, J. Fernandix-Crehuet, M. Thamm, J. J. Strain, F. J. Kok and L. Kohlmeier, unpublished results).

\section{SUMMARY AND CONCLUSION}

What we know about prevention of breast cancer is related to lifetime oestrogen exposure and exposures to specific oestrogens at vulnerable periods of life. This can be influenced by diet. The strongest indicator of a diet-related effect to date is the fairly consistent increase in breast cancer among women who are tall or obese (Hunter \& Willett, 1993). The other dietary factors, summarized in Table 1 are less strongly associated with breast-cancer risk in epidemiological studies.

The relationship between fat and breast-cancer risk has been extensively studied but remains somewhat uncertain. Fat, as a contributor to energy intakes and energy imbalance, is probably a factor in the higher breast-cancer rates in Western countries. Beyond its role as an energy source, the evidence for an independent effect of dietary fat on breast-cancer risk is weak. More focused analyses of the role of individual fatty acids, and on lipidrelated pesticide exposures, may reveal strong effects which are currently masked by the use of inadequate exposure measures, as well as by measurement error.

Currently, there is substantial evidence of a weak relationship with alcohol consumption, even at frequencies of drinking of less than once daily. The evidence of a protective role for antioxidants is weaker for breast cancer than for other cancers. This might by expected in a cancer which is not strongly associated with cigarette smoking. Specific foods are being studied for other potentially-active ingredients which may be 
Table 1. Diet-related factors and the risk of breast cancer

\begin{tabular}{lc}
\hline \hline Energy & $\uparrow$ \\
Height & $\uparrow$ \\
Fat & $\uparrow$ \\
Energy-adjusted fat residuals & - \\
Individual fatty acids & $(\downarrow)$ \\
$n-3$ & $\uparrow ?$ \\
$n-6$ & $\downarrow ?$ \\
$n-9$ & $\uparrow ?$ \\
trans - & $\uparrow ?$ \\
Carbohydrates & - \\
Antioxidants & $?$ \\
Cruciferous vegetables & $\uparrow$ \\
Alcohol & $?$ \\
Xeno-oestrogens & $?$ \\
\hline \hline
\end{tabular}

$\uparrow$, Increased risk; $\downarrow$, reduced risk; -, no evidence of a relationship.

involved in hormone metabolism, but conclusive results for soyabean or cruciferous vegetables are not yet available. Studying these relationships will continue to be a challenge for researchers because of the difficulties in measuring dietary exposures, which is complicated by the uncertainty of the relevant time frame for exposure assessment.

While substantial attention has been focused on studying diet in relation to incidence, the potential for diet to reduce recurrence of breast cancer is thoroughly under-studied. There is little reason to believe that the factors which influence the incidence of breast cancer, perhaps during childhood and puberty, are the same as those which affect recurrence in adulthood. In this area, the very limited evidence available suggests that study of biologically-active fatty acids is promising.

\section{REFERENCES}

Albanes, D. (1987). Total calories, body weight and tumour incidence in mice. Cancer Research 47, $1987-1992$. Ames, B. N., Shigenaga, M. K. \& Hagen, T. M. (1993). Oxidants, antioxidants, and the degenerative disease of aging. Proceedings of the National Academy of Sciences USA 90, 7915-7922.

Ansher, S. S., Dolan, P. \& Bueding, E. (1986). Biochemical effects of dithiolthiones. Food and Chemical Toxicology 24, 405-415.

Astrup, A. V., Buemann, B., Western, P., Toubro, S., Raben, A. \& Christensen, M. J. (1995). Objective assessment of the habitual dietary fat content in patients with obesity (In Danish). Ugesdrift for Laeger 16, 291-294.

Baker, M. E. (1992). Evolution of regulation of steroid-mediated intercellular communication in vertebrates: insight from flavonoids, signals that mediate plant-rhizobia symbiosis. Journal of Steroid Biochemistry and Molecular Biology 41, 301-308.

Barrett-Connor, E. (1991). Nutrition epidemiology: how do we know what they ate? American Journal of Clinical Nutrition 54, 182-187.

Basu, T. K., Hill, G. B., Ng, D., Abdi, E. \& Temple, N. (1989). Serum vitamins A and E, beta-carotene, and selenium in patients with breast cancer. Journal of the American College of Nutrition 8, 524-528.

Bates, C. J. \& Thurnham, D. I. (1991). Biochemical markers of nutrient intake. In Design Concepts in Nutritional Epidemiology, pp. 192-265 [B. M. Margetts and M. Nelson, editors]. Oxford: Oxford University Press.

Birt, D. F., Julius, A. D., White, L. T. \& Pour, P. M. (1989). Enhancement of pancreatic carcinogenesis in hamsters fed a high-fat diet ad libitum and at a controlled calorie intake. Cancer Research 49, 5848-5851.

Birt, D. F., Pelling, J. C., Pour, P. M., Tibbels, M. G., Schweichkert, L. \& Bresnick, E. (1987). Enhanced pancreatic and skin tumorigenesis in cabbage-fed hamsters and mice. Carcinogenesis 8, 913-917.

Block, G., Patterson, B. \& Subar, A. (1992). Fruit, vegetables, and cancer prevention: A review of the epidemiological evidence. Nutrition and Cancer 18, 1-29.

Braden, L. M. \& Carroll, K. K. (1986). Dietary polyunsaturated fat in relation to mammary carcinogenesis in rats. Lipids 21, 285-288.

Bresnick, E., Birt, D. F., Wolterman, K., Wheeler, M. \& Markin, R. S. (1990). Reduction in mammary tumorigenesis in the rat by cabbage and cabbage residue. Carcinogenesis 11, 1159-1163. 
Comstock, G. W., Helzlsouer, K. J. \& Bush, T. L. (1991). Prediagnostic serum levels of carotenoids and vitamin $\mathrm{E}$ as related to subsequent cancer in Washington County, Maryland. American Journal of Clinical Nutrition 53, 260S-264S.

Connett, J. E., Kuller, L. H., Kjelsberg, M. O., Polk, B. F., Collins, G., Rider, A. \& Hulley, S. B. (1989). Relationship between carotenoids and cancer. The Multiple Risk Factor Intervention Trial (MRFIT) Study. Cancer 64, 126-134.

Davis, D. L. \& Bradlow, H. L. (1995). Can environmental oestrogens cause breast cancer? Scientific American October issue, 166-172.

de Schrijver, R. \& Privett, O. S. (1982). Interrelationship between dietary trans fatty acids and the 6- and 9desaturases in the rat. Lipids 17, 27-34.

Dewailly, E., Dodin, S., Verreault, R., Ayotte, P., Sauve, L. \& Morin, J. (1994). High organochlorine body burden in women with oestrogen receptor positive breast cancer. Journal of the National Cancer Institute 86, 232-234.

Falck, F. Y., Ricci, A. Jr, Wolff, M. S., Godbold, J. \& Deckers, J. (1992). Pesticides and polychlorinated biphenyl residues in human breast lipids and their relation to breast cancer. Archives of Environmental Health 47, 143-146.

Garfinkel, L., Boffetta, P. \& Stellman, S. D. (1988). Alcohol and breast cancer: a cohort study. Preventive Medicine 17, 686-693.

Gey, K. F., Brubacher, G. B. \& Sthelin, H. B. (1987). Plasma levels of antioxidant vitamins in relation to ischemic heart disease and cancer. American Journal of Clinical Nutrition 45, 1368-1377.

Harvey, E. B., Schairer, C., Brinton, L. A., Hoover, R. N. \& Faumeni, J. F. Jr (1987). Alcohol consumption and breast cancer. Journal of the National Cancer Institute 78, 657-661.

Helferich, W. G. (1996). Paradoxical effects of the soy phytoestrogen, genistein, on growth of human breast cancer cells in vitro and in vivo. Proceedings of a Meeting on Modulation of Chemical Toxicity and Risk Assessment (In the Press).

Hirohata, T., Shigematsu, T., Nomura, A., Nomura, Y., Horie, A. \& Hirohata, I. (1985). Occurrence of breast cancer in relation to diet and reproductive history: a case-control study in Fukuoka, Japan. National Cancer Institute Monographs 69, 187-190.

Howe, G., Rohan, T., DeCarli, A., Iscovich, J., Kaldor, J., Katsouyanni, K., Marubini, E., Miller, A., Riboli, E., Toniolo, P. \& Trichopoulos, D. (1991). The association between alcohol and breast cancer risk: evidence from the combined analysis of six dietary case control studies. International Journal of Cancer 47, 707-710.

Howe, G. R., Hirohata, T., Hislop, T. G., Iscovish, J. M., Yuan, J. M., Katsouyanni, K., Lubin, F., Marubini, E., Modan, B., Rhohan, T., Toniolo, P. \& Shunzhang, Y. (1990). Dietary factors and risk of breast cancer: combined analysis of 12 case-control studies. Journal of the National Cancer Institute 82, 561-569.

Huang, M.-T. \& Ferraro, T. (1992). Phenolic compounds in food and cancer prevention. In Phenolic Compounds in Food and Their Effects on Health. vol. 2: Antioxidants and Cancer Prevention, ACS Symposium Series 502, pp. 8-33 [M.-T. Huang, C.-T. Ho and C. Y. Lee, editors]. Washington, DC: American Chemical Society.

Hulka, B. S. (1989). Dietary fat and breast cancer: Case-control and cohort studies. Preventive Medicine 18, $180-193$.

Hunter, D. J., Spiegelman, D., Adami, H.-O., Beeson, L., Van den Brandt, P. A., Folsom, A. R., Fraser, G. E., Goldbohm, A., Graham, S., Howe, G. R., Kushi, L. H., Marshall, J. R., McDermott, A., Miller, A. B., Speizer, F. E., Wold, A., Yuan, S.-S. \& Willett, W. (1996). Cohort studies of fat intake and the risk of breast cancer - a pooled analysis. New England Journal of Medicine 334, 356-361.

Hunter, D. J. Willett, W. C. (1993). Diet, size and breast cancer. Epidemiologic Reviews 15, 110-132.

Hunter, D. J. \& Willett, W. C. (1996). Nutrition and breast cancer. Cancer Causes and Control 7, 56-68.

Kardinaal, A. F. M., van't Veer, P., Kok, F. J., Kohlmeier, L., Martin-Moreno, J. M., Huttunen, J. K., Hallen, M., Aro, A., Galvex, R., Gomez-Aracena, J., Kark, J. D., Martin, B. C., Mazaev, V. P., Riemersma, R. A., Ringstad, J., Strain, J. J. \& Zatonsky, W. (1993). EURAMIC Study: Antioxidants, myocardial infarction and breast cancer. European Journal of Clinical Nutrition 47, Suppl. 2, $64-71$.

Kinsella, J. E., Hwang, D. H., Yu, P., Mai, J. \& Shrimp, J. (1979). Prostaglandins and their precursors in tissues from rats fed on trans, trans-lineolate. Biochemical Joumal 184, 701-704.

Knekt, P. (1988). Serum vitamin E level and risk of female cancers. International Journal of Epidemiology 17, 281-288.

Kohlmeier, L. (1997). Biomarkers of fatty acid exposure and breast cancer risk. American Journal of Clinical Nutrition (In the Press).

Kohlmeier, L. \& Kohlmeier, M. (1995). Adipose tissue as a medium for epidemiologic exposure assessment. Environmental Health Perspectives 103, Suppl. 3, 99-106.

Kohlmeier, L., Simonsen, N., Margolin, B. \& Thamm, M. (1995). Stores of trans fatty acids and breast cancer risk. American Journal of Clinical Nutrition 61, 896.

Koletzko, B. (1992). Trans fatty acids may impair biosynthesis of long-chain polyunsaturates and growth in man. Acta Paediatrica 81, 302-306. 
Krieger, N., Wolff, M. S., Hiatt, R. A., Rivera, M., Vogelman, J. \& Orentreich, N. (1994). Breast cancer and serum organochlorines: a prospective study among white, black and Asian women. Journal of the National Cancer Institute 86, 589-599.

LaVecchia, C., Negri, E., Franceschi, S., Decarli, A., Giacosa, A. \& Lipworth, L. (1995). Olive oil, other dietary fats, and the risk of breast cancer (Italy). Cancer Causes and Control 6, 545-550.

Lawson, L. D., Hill, E. G. \& Holman, R. T. (1983). Suppression of arachidonic acid in lipids of rat tissues by dietary mixed isometrics and trans octadecenoates. Journal of Nutrition 113, 1827-1835.

Lichtman, S. W., Pisarska, K., Berman, E. R., Prestone, M., Dowling, H., Offenbacher, E., Weisel, H., Heshka, S., Matthews, D. E. \& Heymsfield, S. B. (1992). Discrepancy between self-reported and actual caloric intake and exercise in obese subjects. New England Journal of Medicine 327, 1893-1898.

Lobbezzoo, I. E., van't Veer, P., Martin-Moreno, J. M., Guallar, E. L., Gomez-Aracena, J., Kardinaal, A. F. M., Kohlmeier, L., Martin, B. C., Strain, J. J., Thamm, M., van Zoonen, P., Baumann, B. A. \& Kok, F. J. (1997). Adipose DDE and risk of post-menopausal breast cancer in Europe: the EURAMIC study. British Medical Journal (In the Press).

London, S. J., Sacks, F. M., Caesar, J., Stampfer, M. J., Siguel, E. \& Willett, W. C. (1991). Fatty acid composition of subcutaneous adipose tissue and diet in post-menopausal US women. American Journal of Clinical Nutrition 54, 340-345.

London, S. J., Sacks, F. M., Stampfer, M. J., Henderson, I. C., Madwe, M., Tomita, A., Wood, W. C., Remine, C., Robert, N. J., Dmochowski, R. \& Willett, W. (1993). Fatty acid composition of subcutaneous adipose tissue and risk of proliferative benign breast disease and breast cancer. Journal of the National Cancer Institute 85, 785-793.

Longnecker, M. P. (1994). Alcoholic beverage consumption in relation to risk of breast cancer: meta-analysis and review. Cancer Causes and Control 5, 73-82.

Longnecker, M. P., Newcomb, P. A., Mittendorf, R., Greenberg, R. E., Clapp, R. W., Bogdan, G. F., Baron, J., MacMahon, B. \& Willett, W. C. (1995a). Risk of breast cancer in relation to lifetime alcohol consumption. Journal of the National Cancer Institute 12, 923-929.

Longnecker, M. P., Paganini-Hill, A. \& Ross, R. K. (1995b). Lifetime alcohol consumption and breast cancer risk among post-menopausal women in Los Angeles. Cancer Epidemiology Biomarkers and Prevention 4, 721-725.

Lu, L. W., Anderson, K. E., Grady, J. J. \& Nagamani, M. (1996). Effects of soya consumption for one month on steroid hormones in premenopausal women: Implications for breast cancer risk reduction. Cancer Epidemiology, Biomarkers and Prevention 5, 63-70.

McDanell, R., McLean, A. E., Hanley, A. B., Heaney, R. K. \& Fenwick, G. R. (1989). The effect of feeding Brassica vegetables and intact glucosinolates on mixed-function-oxidase activity in the livers and intestines of rats. Food and Chemical Toxicology 27, 289-293.

Mahfouz, M. M., Smith, T. L. \& Kummerow, F. A. (1984). Effect of dietary fats on desaturase activities and the biosynthesis of fatty acids in rat-liver microsomes. Lipids 19, 214-222.

Martin-Moreno, J. M., Willett, W. C., Gorgojo, L., Banegas, J. R., Rodriguez-Artalejo, F., Fernandez-Rodriguez, J. C., Maisonneuve, P. \& Boyle, P. (1994). Dietary fat, olive oil intake and breast cancer risk. International Journal of Cancer 58, 774-780.

Marubini, E., Decarli, A., Costa, A., Mazzoleni, C., Andreoli, C., Barbieri, A., Capitelli, E., Carlucci, M., Cavallo, F., Monferroni, N., Pastorino, U. \& Salvini, S. (1988). The relationship of dietary intake and serum levels of retinol and beta-carotene with breast cancer. Cancer 61, 173-180.

Messina, M. J., Persky, V., Setchell, K. D. R. \& Barnes, S. (1994). Soy intake and cancer risk.: A review of the in vitro and in vivo data. Nutrition and Cancer 21, 113-131.

Michnovicz, J. J. \& Bradlow, H. L. (1991). Altered oestrogen metabolism and excretion in humans following consumption of indole-3-carbinol. Nutrition and Cancer 16, 59-66.

Newfield, L., Goldsmith, A., Bradlow, H. L. \& Auborn, K. (1993). Oestrogen metabolism and human papillomavirus-induced tumors of the larynx: Chemo-prophylaxis with indole-3-carbinol. Anticancer Research 13, 337-341.

Nogushi, M., Rose, D. P., Earashi, M. \& Miyazaki, I. (1995). The role of fatty acids and eicosanoid synthesis inhibitors in breast carcinoma. Oncology 52, 265-271.

Olsen, S. F., Hansen, H. S., Sandström, B. \& Jensen, B. (1995). Erythrocyte levels compared with reported dietary intake of marine $n-3$ fatty acids in pregnant women. British Journal of Nutrition 73, 387-395.

Paganini-Hill, A., Chao, A., Ross, R. K. \& Henderson, B. E. (1987). Vitamin A, $\beta$-carotene, and the risk of cancer: a prospective study. Journal of the National Cancer Institute 79, 443-448.

Palmgren, J. (1993). Controlling for total energy intake in regression models for assessing macronutrient effects on disease. European Joumal of Clinical Nutrition 47, Suppl. 2, S46-S50.

Potischman, M., McCulloch, C. E., Byers, T., Nemoto, T., Stubbe, N., Milch, R., Parker, R., Rasmussen, K. M., Root, M., Graham, S. \& Campbell, T. C. (1990). Breast cancer and dietary and plasma concentrations of carotenoids and vitamin A. American Journal of Clinical Nutrition 52, 909-915.

Prentice, R. L., \& Sheppard, L. (1989). Validity of international, time trend, and migrant studies of dietary factors and disease risk. Preventive Medicine 18, 167-179. 
Prestera, T., Holtzclaw, W. D., Zhang, Y. \& Talalay, P. (1993). Chemical and molecular regulation of enzymes that detoxify carcinogens. Proceedings of the National Academy of Sciences USA 90, 2965-2969.

Reichman, M. E., Judd, J. T., Longcope, C. \& Schatzkin, A. (1993). Effects of alcohol consumption on plasma and urinary hormone concentrations in premenopausal women. Journal of the National Cancer Institute $\mathbf{8 5}$, $722-727$.

Rohan, T. E., McMichael, A. J. \& Baghurst, P. A. (1988). A population-based case-control study of diet and breast cancer in Australia. American Journal of Epidemiology 128, 478-489.

Safe, S. H. (1995). Environmental and dietary estrogens and human health: Is there a problem? Environmental Health Perspectives 103, 346-351.

Scholar, E. M., Wolterman, K., Birt, D. F. \& Bresnick, E. (1989). The effect of diets enriched in cabbage and collards on urine pulmonary metastasis. Nutrition and Cancer 12, 121-126.

Simonsen, M., Strain, J. J., van't Veer, P., Kardinaal, A., Fernandez-Crehuet, J., Huttunen, J., Martin-Moreno, J. M., Martin, B., Thamm, M., Kok, F. \& Kohlmeier, L. (1996). Adipose tissue $\omega-3$ fatty acids and breast cancer in a population of European women. American Journal of Epidemiology 143, Suppl. 135Abstr.

Stoewsand, G. S., Anderson, J. L. \& Munson, L. (1988). Protective effect of dietary Brussels sprouts against mammary carcinogenesis in Sprague-Dawley rats. Cancer Letters 39, 199-207.

Sutherland, S. E., Benard, V. B., Keil, J. E., Austin, H. \& Hoel, D. G. (1996). Pesticides and twenty-year risk of breast cancer. American Journal of Epidemiology 143, Suppl., 135Abstr.

Telang, N. T., Bradlow, H. L. \& Osborne, M. P. (1992). Molecular and endocrine biomarkers in non-involved breast: Relevance to cancer chemoprevention. Journal of Cellular Biochemistry 16G, Suppl., 161-169.

Temple, N. J. \& Basu, T. K. (1987). Selenium and cabbage and colon carcinogensis in mice. Journal of the National Cancer Institute 79, 1131-1134.

Temple, N. J. \& el Khatib, S. M. (1987). Cabbage and vitamin E: their effect on colon tumour formation in mice. Cancer Letters 35, 71-77.

Thomas, D. B. (1995). Alcohol as a cause of cancer. Environmental Health Perspectives 103, 153-160.

Toniolo, P., Riboli, E., Protta, F., Charrel, M. \& Cappa, A. P. M. (1989). Breast cancer and alcohol consumption: a case-control study in Northern Italy. Cancer Research 49, 5203-5206.

Trichopolou, A., Katsouyanni, K., Stuver, S., Tzala, L., Gnardellis, C., Rimm, E. \& Trichopoulos, D. (1995). Consumption of olive oil and specific food groups in relation to breast cancer risk in Greece. Journal of the National Cancer Institute 87, 110-116.

van't Veer, P., Kok, F. J., Hermus, R. J. \& Sturmans, F. (1989). Alcohol dose, frequency and age at first exposure in relation to the risk of breast cancer. Intermational Journal of Epidemiology 18, 511-517.

van't Veer, P., Strain, J. J., Fernandez-Crehuet, J., Martin, B. C., Thamm, M., Kardinaal, A. F. M., Kohlmeier, L., Huttunen, H. K., Martin-Moreno, J. M. \& Kok, F. J. (1996). Tissue antioxidants and post-menopausal breast cancer: The European Community multicentre study on antioxidants, myocardial infarction and cancer of the breast (EURAMIC). Cancer Epidemiology, Biomarkers and Prevention 5, 441-447.

Wald, N. J., Boreham, J., Hayward, J. L. \& Bulbrook, R. D. (1984). Plasma retinol, beta-carotene and vitamin E levels in relation to future risk of breast cancer. British Journal of Cancer 49, 321-324.

Wald, N. J., Thompson, S. G., Densem, J. W., Boreham, J. \& Bailey, A. (1988). Serum beta-carotene and subsequent risk of cancer: Results from the BUPA Study. British Journal of Cancer 57, 428-433.

Wattenberg, L. W. (1983). Inhibition of neoplasia by minor dietary constituents. Cancer Research 43, 2448S2453S.

Willett, W. C., Polk, F., Underwood, B. A., Stampfer, M. J., Pressel, S., Rosner, B., Taylor, J. O., Schneider, K. \& Hames, C. G. (1984). Relation of serum vitamin A and E and carotenoids to the risk of cancer. New England Journal of Medicine 310, 430-434.

Wolff, M. S. \& Toniolo, P. (1995). Environmental organochlorine exposure as a potential etiologic factor in breast cancer. Environmental Health Perspectives 103, Suppl. 7, 141-145.

Wolff, M. S., Toniolo, P., Lee, E., Rivera, M. \& Dubin, N. (1993). Blood levels of organochlorine residues and risk of breast cancer. Journal of the National Cancer Institute 85, 648-652.

Young, T. B. (1989). A case control study of breast cancer and alcohol consumption habits. Cancer 64, 552-558. 